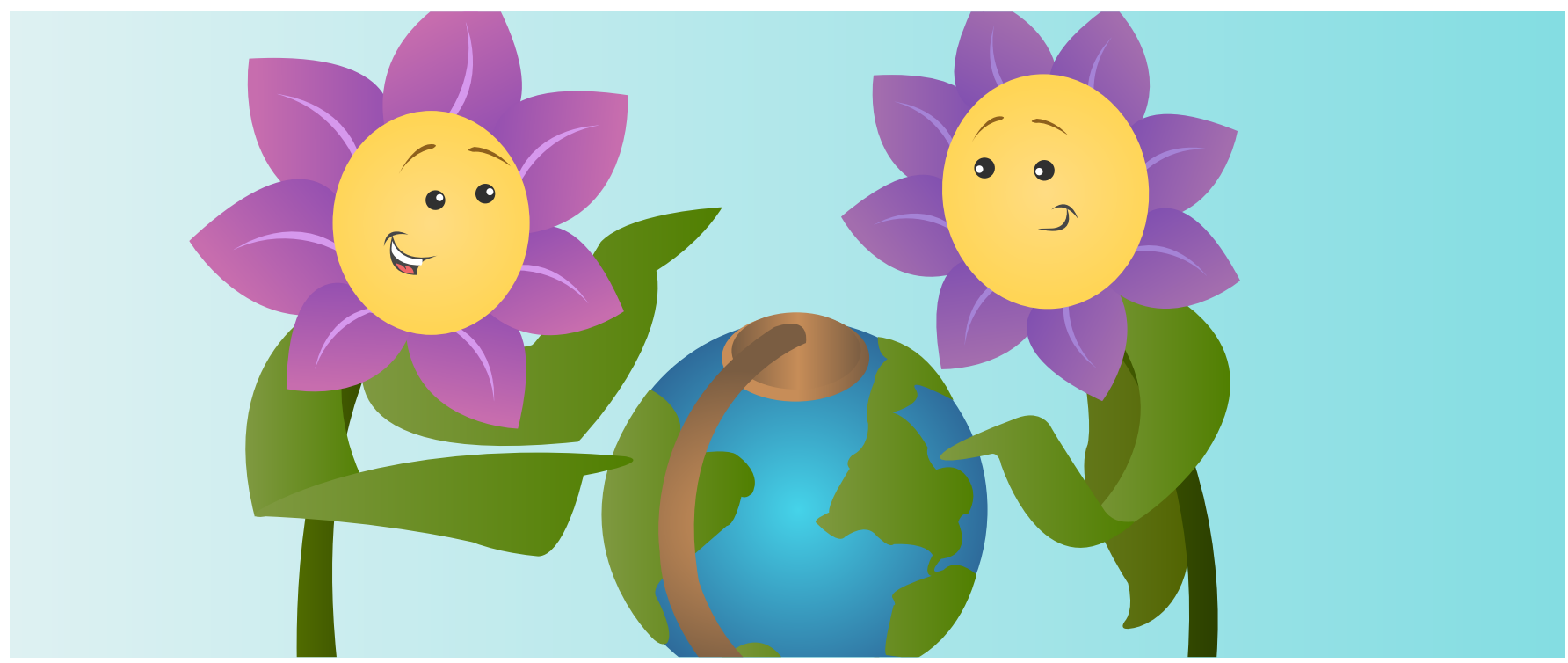

\title{
DON'T JUDGE A PLANT BY ITS FLOWERS
}

\section{Riva Anne Bruenn ${ }^{1 *}$, Valerie Lavenburg ${ }^{2}$ and Shayla Salzman ${ }^{3}$}

${ }^{1}$ Plant and Microbial Biology Department, University of California, Berkeley, Berkeley, CA, United States, ${ }^{2}$ Integrative Biology Department, University of California, Berkeley, Berkeley, CA, United States, ${ }^{3}$ Organismic and Evolutionary Biology Department, Harvard University, Cambridge, MA, United States

\section{REVIEWED BY:}

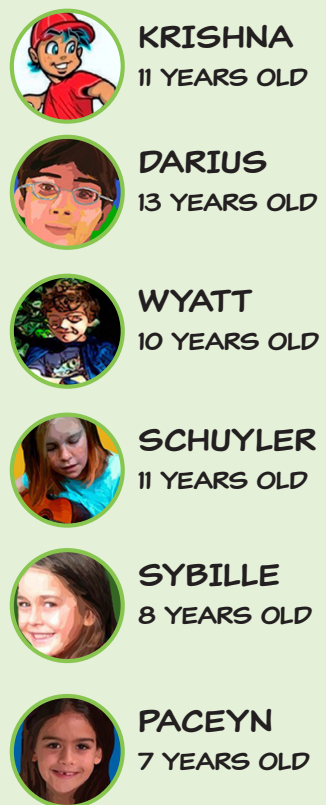

You may have noticed that there are lots of different kinds of plants in your own backyard or neighborhood, and you may even have heard of the concept of evolution. But have you ever wondered what forces have contributed to creating all these plants, with different shapes and colors, all over the world? Or how scientists hope to understand and explain how so many kinds of life came to be over millions of years? Using a mysterious case of look-alike flowers living on opposite sides of an ocean, we will show the way researchers piece together evolutionary histories by using plant DNA and the knowledge of what plants look like today. Let us build a scientific time machine and solve the mystery!

\section{A WORLD OF PLANTS}

If you look around, you will notice that there are different kinds of plants everywhere. Plants are the foundation of every ecosystem, from tundras to tropical rain forests and wetlands, even deserts! In these different ecosystems, there are plants of different shapes and sizes. When we talk about the appearance of a plant or its parts (like the shape or color of 
MORPHOLOGY (MORE-FALLUH-GEE)

The physical traits of an organism, like color or shape.

EVOLUTION (EHVOH-LOO-SHUN)

The study of how life develops and diversifies over time.

SPECIES

(SPEE-SEES)

A group of similar organisms, considered to be all of the same type.

PHYLOGENETIC (FIE-LOH-GENEH-TICK) TREES

Diagrams scientists use to show evolutionary relationships between organisms.

HOMOLOGY

(HOME-ALLUH-GEE)

When multiple organisms share a trait because that trait was passed down from a common ancestor.

CONVERGENCE (CUHN-VERGEENCE)

When a trait shared between organisms was not present in their common ancestor. In convergence, this shared trait evolved independently. a flower), we are describing its morphology: the physical traits of the organism. How has this incredible variety in morphology of plants come to exist? Scientists answer questions like this through evolution. Evolution explains how living things are related to each other, and how their ancient history led to the many different organisms in different parts of the world today.

The plants of today have all evolved from ancestors that may have looked different or may have passed down parts of their morphology to present generations, much like how you may have eyes like your mother's or a nose like your father's. Plants' morphology, where they grow, their DNA, and even plant fossils are used to trace the history of how present-day plants evolved. Understanding plant evolution is important! Studying evolution increases our knowledge of the living things on our planet and aids in the discovery of new species. A species is a group of organisms that are similar enough that we consider them all the same type of organism. Lions and giraffes are examples of animal species. Scientists trying to protect the variety of life on Earth use knowledge of the number of species and where they live to decide how to focus their efforts. Analyzing how plant species evolved in different regions and climates throughout history can help scientists understand how plants may respond to the changing climate and predict how the world will look in the future.

\section{TREE BASICS}

Scientists use diagrams called phylogenetic trees (Figure 1), similar to a family tree, to show evolutionary relationships between ancestors (similar to grandparents) and their descendants (similar to children). In a phylogenetic tree, all the organisms that descended from a common ancestor are grouped in a clade. The common ancestor of two or more organisms is found by following the lines from those organisms backward until they all meet at one point, which is called a node. If a trait of a common ancestor has been passed down to multiple descendants, this is called homology. By contrast, convergence describes a shared trait between two organisms that was not present in their common ancestor. In convergence, these shared traits actually evolved independently in both organisms [1]. In Figure 1, if you follow the lines from hummingbirds and sunbirds to their common ancestor, you can see that the common ancestor of birds had wings. Wings were passed down from that common ancestor to both birds, making sunbird and hummingbird wings a case of homology. However, if you follow the lines from bats, hummingbirds, and sunbirds all the way back to the common ancestor of birds and mammals, this ancestor did not have wings and thus could not have passed wings down to birds and bats. This means that bat wings and bird wings are a case of convergence. One clue that bat and bird wings are a case of convergence is that bird wings have feathers and bat wings do not. Bats have evolved a different way to fly. 


\section{FIGURE 1}

Understanding a

phylogenetic tree.

The animals with red labels (hummingbirds, sunbirds, and bats) share the trait of having wings. Wings in hummingbirds and sunbirds are a case of homology, because their common ancestor, another bird, also had wings with feathers. The common ancestor of the clade of birds and the clade of mammals, however, did not have wings and so bat wings and bird wings are an example of evolutionary convergence. You might guess this because bat wings are similar to bird wings in some ways (they are used to fly) but also different in some ways (bat wings do not have feathers).

\section{POLLINATOR}

(PAUL-IN-ATE-ER)

An animal that carries pollen between flowers, helping plants to reproduce.

\section{POLLINATION}

\section{GENERALIST}

(JEN-ER-AH-LIST)

A plant whose flowers are pollinated by many different animals.

\section{POLLINATION SYNDROME (SIN-DROHM)}

The common morphology of flowers that evolved to attract a specific pollinator.

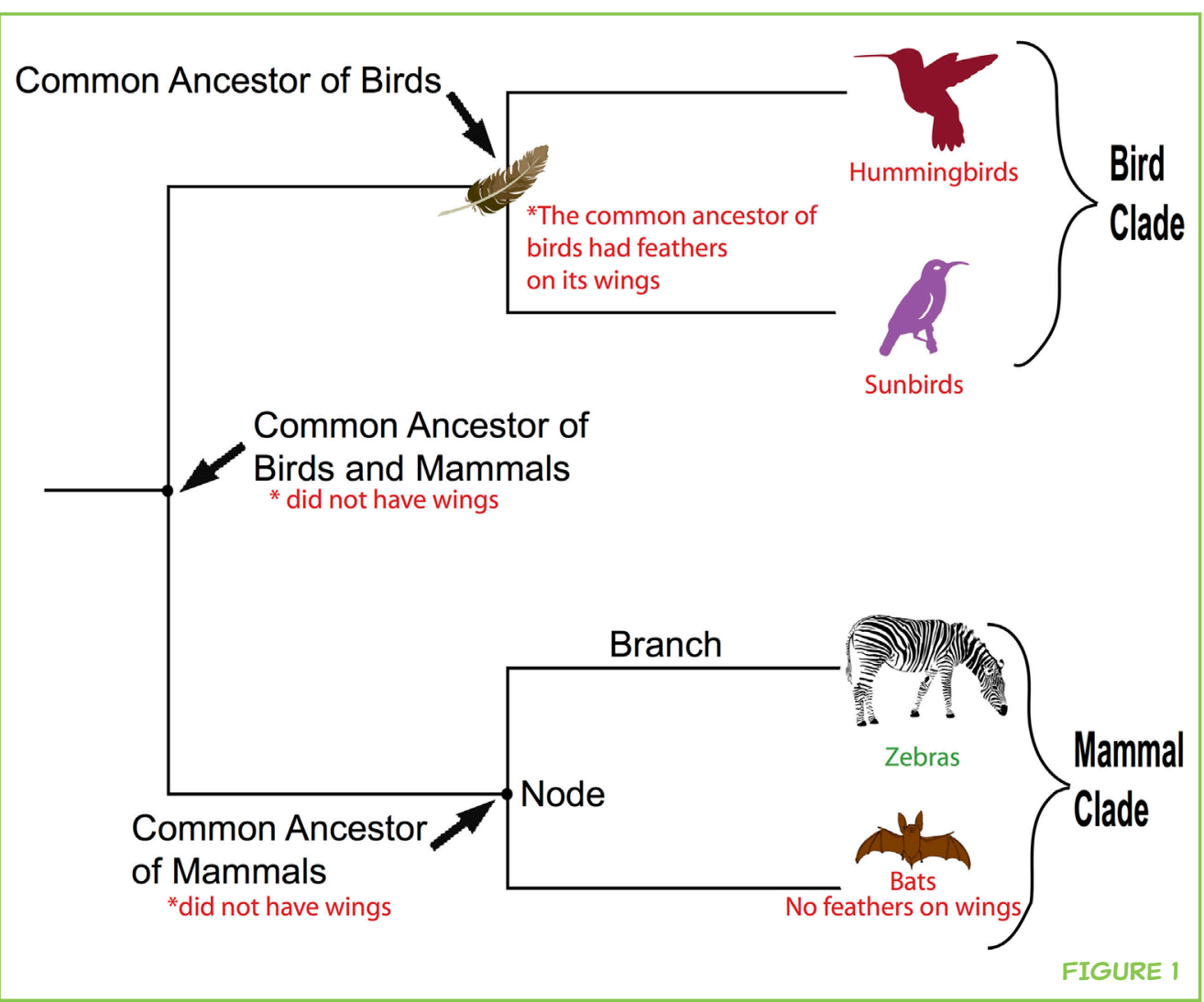

\section{A LOOK AT COSTACEAE}

The Costaceae (cost-ACE-ee), commonly known as the spiral gingers, is a group of plants with about 120 species [2]. Costaceae species grow in the tropics across Africa, Asia, and Central and South America. Like many flowering plants, species in the Costaceae use pollinators, animals that carry pollen between flowers, to help them reproduce. Many Costaceae species are pollination generalists, meaning that many different animals pollinate their flowers. However, bees pollinate some species best, whereas birds are the only pollinators of others $[2,3]$. Flowers that are pollinated by the same animals tend to have some of the same morphology [4]. For example, flowers pollinated by flies often look or smell like rotting meat. The common morphology of flowers that evolved to attract a specific pollinator is called a pollination syndrome.

\section{LOOK-ALIKE FLOWERS ACROSS AN OCEAN}

There are bird-pollinated species of Costaceae in both Southeast Asia and Central and South America (the tropical Americas). In Asia, sunbirds pollinate Costaceae flowers. In the tropical Americas, hummingbirds pollinate some Costaceae flowers [3]. Although these plants live far apart and use different pollinators, their flowers look alike and share a similar morphology (Figures 2B,C). Bird-pollinated flowers in both places are bright red, yellow, or orange. They are shaped like narrow tubes, so that 
FIGURE 2

Some species of Costaceae with symbols to show their pollination syndromes.

A. Costus guanaiensis is bee-pollinated. Do you see the yellow landing strips for bees to follow?

B. C. comosus is hummingbird-pollinated. Do you see the orange tube-like flowers?

C. Tapeinochilos ananassae is sunbirdpollinated. Do you see the yellow tube-like flowers?

D. Chamaecostus

cuspidatus does not have a specific pollination syndrome. It is pollinated by many different insects, what we call generalist pollination. You can think of it like a big dinner plate that everyone can eat off. The flowers in $\mathbf{A}$. and $\mathbf{B}$. live close together. The flowers in $\mathbf{B}$. and $\mathbf{C}$. live across the ocean. Which flowers look the most similar? What similarities do you see?

\section{HYPOTHESIS}

(HI-POTH-EH-SIS)

A prediction based on available evidence, which can be tested through experiments.
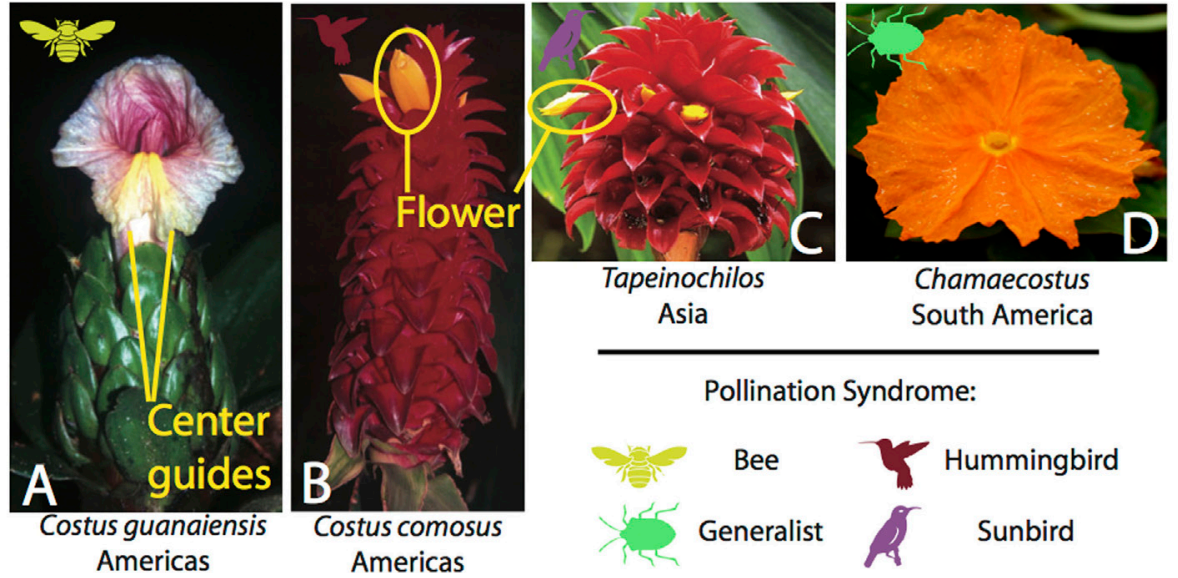

Chamaecostus

South America

Pollination Syndrome:

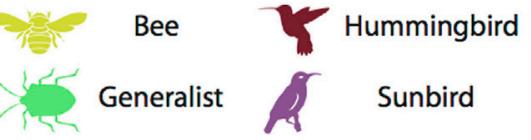

FIGURE 2

the long bills of birds can fit inside to drink nectar while their bodies pick up and transfer pollen [5]. By contrast, bee-pollinated Costaceae species have larger flowers with wide openings for bees to crawl inside (Figure 2A). The bee-pollinated flowers are usually light pink, yellow, or white and have markings that guide bees to their centers [6]. The flowers we chose for Figure 2 look very similar to other Costaceae flowers with the same pollination syndromes.

Brightly colored and tube-like flowers are said to have a bird pollination syndrome, whereas lightly colored and wide flowers with center guides for bees are said to have a bee pollination syndrome. We know these pollination syndromes match their pollinators, because researchers have watched to see which animals visited flowers and which animals were best at transferring pollen from these flowers [6].

Species of Costaceae present an evolutionary mystery! Why do some species living in the tropical Americas look so much like species living far away in South East Asia? In this paper, we will combine knowledge of the evolutionary relationships of Costaceae species with our knowledge of the different pollination syndromes to answer a central question: do birdpollinated species in Asia and the tropical Americas look alike because of homology, or convergence?

\section{FORMING A HYPOTHESIS}

Scientists form a hypothesis to guide their research. A hypothesis is a testable prediction based on available evidence. In the case of Costaceae and its pollination syndromes, researchers tested the following hypothesis:

Hummingbird-and sunbird-pollinated species have similar looking flowers because they inherited their shared floral traits from a common ancestor (Homology). 


\section{FIGURE 3}

The phylogenetic tree of Costaceae species. All of the species names are listed to the right and are labeled with their pollination syndrome: generalist, bee, or bird. You can see our two bird-pollinated species that started this mystery by the photos to the right of their names. The first thing to notice is that they are not close to each other at all. There are many other species in between them and so they are not closely related! Now, if you follow all of the branches (the lines) of the tree back from our two suspects to where they meet, you are all the way at the left side of the tree, the end. This is the common ancestor of all Costaceae who probably lived millions of years ago! Our ancestral state reconstruction shows that this ancestor most likely had a generalist pollination syndrome, which is noted with a generalist label. All of the other labels that you see on the tree are nodes, where that labeled pollination syndrome evolved in history. This means that there was an ancestor that lived long ago with that pollination morphology. There are five evolutions of bee pollination, nine evolutions of hummingbird pollination, and one evolution of sunbird pollination. And we can see that bee pollination evolved before hummingbird pollination.
If our hypothesis is correct, the following statements would have to be true:

1. Hummingbird- and sunbird-pollinated species are closely related.

2. The common ancestor of hummingbird- and sunbird-pollinated species had a bird pollination syndrome.

\section{GATHERING CLUES TO SOLVE THE MYSTERY}

\section{LET'S TEST OUR HYPOTHESIS! ARE HUMMINGBIRD- AND SUNBIRD-POLLINATED SPECIES CLOSELY RELATED?}

To find out, we need to know the evolutionary relationships of species within Costaceae. Species that are closely related have more similar DNA sequences than species that are less related. Researchers can use the sequences of DNA to predict the evolutionary relationships of organisms by building a phylogenetic tree like the one for Costaceae (Figure 3). In our phylogenetic tree, each species has the symbol of its pollinator next to its name. Find the bird-pollinated species. As you can see, there are many hummingbirdpollinated species (toward the bottom), but only one sunbird-pollinated

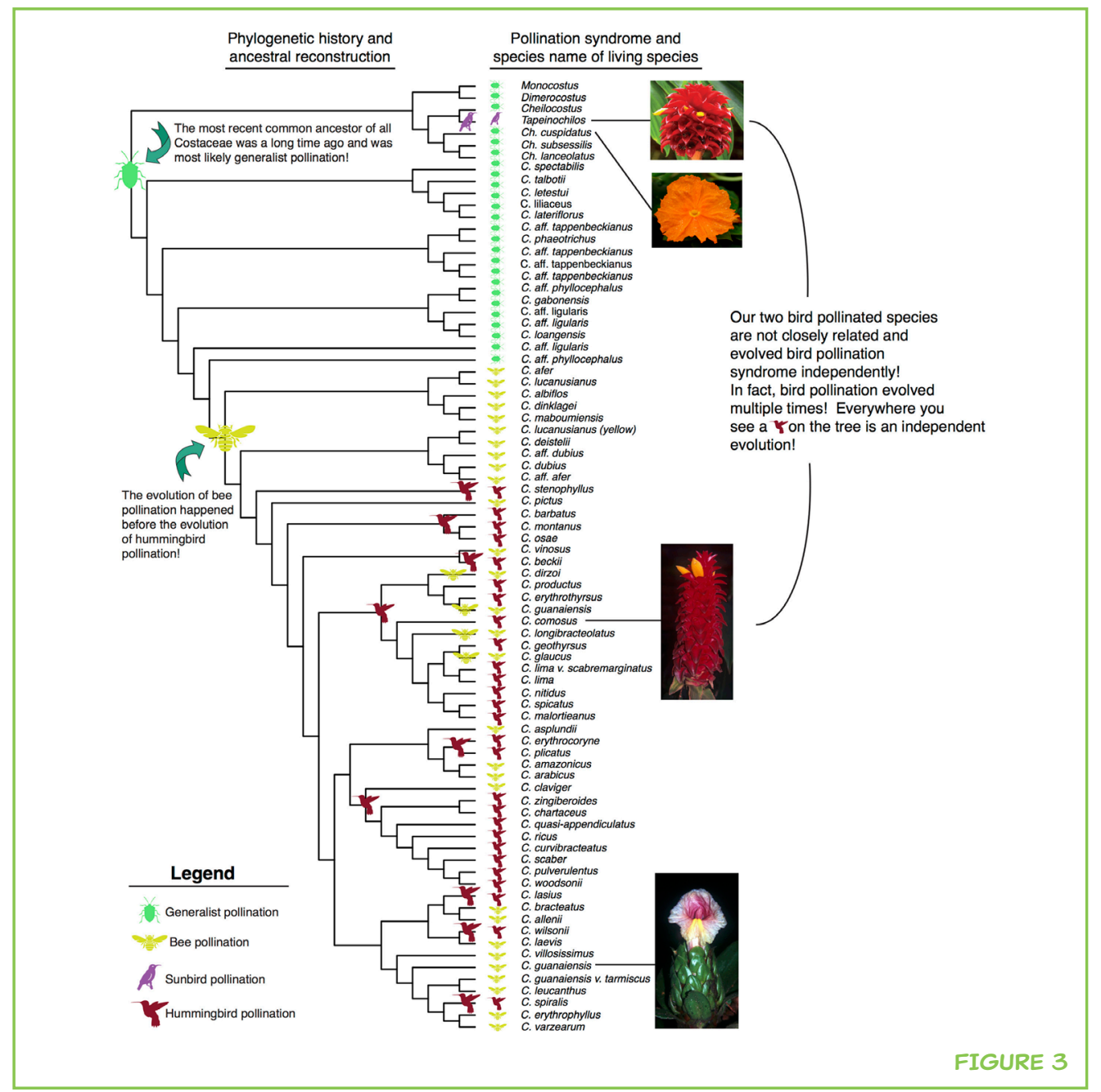


ANCESTRAL

(AN-SEST-RAL)

STATE

RECONSTRUCTION

(REE-CAHN-

STRUKT-SHUN)

This technique uses mathematical tests and knowledge of the traits of present-day species to predict what traits their ancestors possibly had. species in our phylogenetic tree (toward the top). The most recent common ancestor of all the Costaceae is the place where the lines from our birdpollinated flowers Tapeinochilos and Costus comosus meet, all the way on the left (Figure 3). There have been many splits in the tree since the most recent common ancestor, leading to some species that are bee-pollinated, some that are pollination generalists, and some that are bird pollinated. Notice how many splits there are in our phylogenetic tree between the line leading to Tapeinochilos and the line leading to C. comosus. Does the phylogenetic tree support our hypothesis? Are hummingbird- and sunbird-pollinated species closely related? The answer is no! These two species are not closely related.

\section{DID THE COMMON ANCESTOR OF HUMMINGBIRD- AND SUNBIRD- POLLINATED SPECIES HAVE A BIRD POLLINATION SYNDROME?}

To predict the pollination syndrome of the common ancestor, researchers use a method known as ancestral state reconstruction. This technique uses mathematical tests and knowledge of the traits of present-day species to predict what traits ancestors possibly had. The results of an ancestral state reconstruction show us the probability, or likelihood, which an ancestor had a certain trait.

The results of an ancestral state reconstruction of pollination syndrome in Costaceae reveal that the common ancestor of hummingbird- and sunbirdpollinated species was probably not bird pollinated, but more of a pollination generalist likes Chamaecostus (Figures 2 and 3) [7]. Not only did bird pollination in general evolve more than once in Costaceae, but hummingbird pollination itself also evolved multiple times! These data do not support our hypothesis that shared bird pollination syndromes are due to homology.

Our data and analyses did not support our hypothesis. Even though hummingbird- and sunbird-pollinated flowers look-alike, this does not mean that these traits were passed down from a common ancestor-instead, they are likely the result of convergence. It is most likely that these plants independently evolved similar morphology to help with bird pollination, such as their tubular flowers and their bright colors. Who would have guessed that the two very similar flowers in Figures $2 \mathrm{~B}, \mathrm{C}$ are not closely related and are an example of evolutionary convergence?

\section{LET'S DIVE DEEPER!}

You may have noticed that the results of our ancestral state reconstruction were in probabilities. Why do we say the common ancestor probably was a pollination generalist instead of saying it was a generalist? Since we do not have a true time machine, we can only estimate the morphology of ancestral species. Just as detective figures out how a crime may have happened from bits of evidence, we piece together how Costaceae species may have evolved by using our own evidence. Our bits of evidence are the pollination syndromes of present-day plants (the symbols next to their 
names on the phylogenetic tree) and a phylogenetic tree. In the case of Costaceae pollination, our detective work does not point to a common ancestor with bird pollination syndrome, but rather tells us that bird pollination evolved multiple times independently.

What led to convergence in the evolution of Costaceae bird pollination syndrome? The evolution of all organisms is influenced by the environment in which they live, such as the climate and/or the other animals and plants nearby. A species must survive and reproduce under these environmental conditions or it will eventually go extinct. The evolution of new morphologies may improve an organism's ability to survive in its environment or improve its chances of reproducing and passing on its DNA. In Asia and the tropical Americas, there are groups of birds that work as pollinators. Perhaps these sunbirds and hummingbirds were looking for flower nectar as a food source and found Costaceae flowers. At this time in history, the flowers probably had wide floral tubes that were bee pollinated. There is always some variation in the morphology of a species. Just as humans do not all look the same; these flowers would not have all been exactly the same shape. While birds would have tried to get nectar from all flowers, those with the longest, most narrow tubes would have been the easiest to drink from and were therefore the most likely to be pollinated by birds instead of bees. The widest flowers would be the easiest to crawl into, and therefore the most likely to be pollinated by bees. Over time, birds kept choosing the narrowest, most tubular flowers and bees kept choosing the widest, most open flowers. Because of these choices, pollen no longer got transferred between the wide flowers and the narrow flowers. Wide flowers only reproduced with wide flowers and narrow with narrow. Eventually, two separate species with these different floral traits were formed. In this way, closely related species can live near each other but look very different, like beeand hummingbird-pollinated species in the Costaceae (Figures 2A,B). In both Asia and the tropical Americas, birds were the environmental factor that put pressure on some Costaceae plants and caused the evolution of traits we call the bird pollination syndrome. You can see how effective this environmental pressure can be by the incredible convergence in pollination syndrome seen in Figures 2B,C!

Studies like these give us a glimpse into the past, revealing the process of evolution and how new species arise. In order to look back in time, we need to combine an understanding of the DNA and morphology of plants as well as knowledge of mathematics. Using this scientific time machine, we can explore what ancient organisms might have looked like, and how they contributed to present-day variety in living things.

\section{REFERENCES}

1. Understanding Evolution. 2016. University of California Museum of Paleontology. Available at: http://evolution.berkeley.edu/ 
2. Specht, C. D. 2006. Systematics and evolution of the tropical monocot family Costaceae (Zingiberales): a multiple dataset approach. Syst. Bot. 31(1):89-106. doi:10.1600/036364406775971840

3. Salzman, S., Driscoll, H. E., Renner, T., André, T., Shen, S., and Specht, C. D. 2015. Spiraling into history: a molecular phylogeny and investigation of biogeographic origins and floral evolution for the genus Costus. Syst. Bot. 40(1):104-15. doi:10.1600/036364415X686404

4. Fenster, C. B., Armbruster, W. S., Wilson, P., Dudash, M. R., and Thomson, J. D. 2004. Pollination and floral syndromes. Annu. Rev. Ecol. Evol. Syst. 35:375-403. doi:10.2307/annurev.ecolsys.34.011802.30000015

5. Kay, K. M., and Schemske, D. W. 2003. Pollinator assemblages and visitation rates for 11 species of neotropical Costus (Costaceae). Biotropica 35(2):198-207. doi:10.1111/j.1744-7429.2003.tb00279.x

6. Specht, C. D., Kress, W. J., Stevenson, D. W., and DeSalle, R. 2001. A molecular phylogeny of Costaceae (Zingiberales). Mol. Phylogenet. Evol. 21(3):333-45. doi:10.1006/mpev.2001.1029

7. Specht, C. D., Yockteng, R., Almeida, A. M., Kirchoff, B. K., and Kress, W. J. 2012. Homoplasy, pollination, and emerging complexity during the evolution of floral development in the tropical gingers (Zingiberales). Bot. Rev. 78(4):440-62. doi:10.1007/s12229-012-9111-6

SUBMITTED: 07 October 2016; ACCEPTED: 16 June 2017; PUBLISHED ONLINE: 06 July 2017.

EDITED BY: Chelsea D. Specht, University of California, Berkeley, United States

CITATION: Bruenn RA, Lavenburg V and Salzman S (2017) Don't Judge a Plant by Its Flowers. Front. Young Minds 5:31. doi:10.3389/frym.2017.00031

CONFLICT OF INTEREST STATEMENT: The authors declare that the research was conducted in the absence of any commercial or financial relationships that could be construed as a potential conflict of interest.

COPYRIGHT @ 2017 Bruenn, Lavenburg and Salzman. This is an open-access article distributed under the terms of the Creative Commons Attribution License (CC BY). The use, distribution and reproduction in other forums is permitted, provided the original author(s) or licensor are credited and that the original publication in this journal is cited, in accordance with accepted academic practice. No use, distribution or reproduction is permitted which does not comply with these terms.

\section{REVIEWED BY}

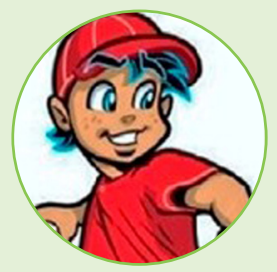

\section{KRISHNA, $\|$ YEARS OLD}

I love science and sports. I play baseball and learning kung-fu. I love to do experiments to understand how science works. In science, I enjoy space/astronomy and physics. I enjoy reading a lot and hope to write lot of kids' books (I have started on three already). In my life, I want to invent something new and bring back to life something that is extinct-using DNA research. 

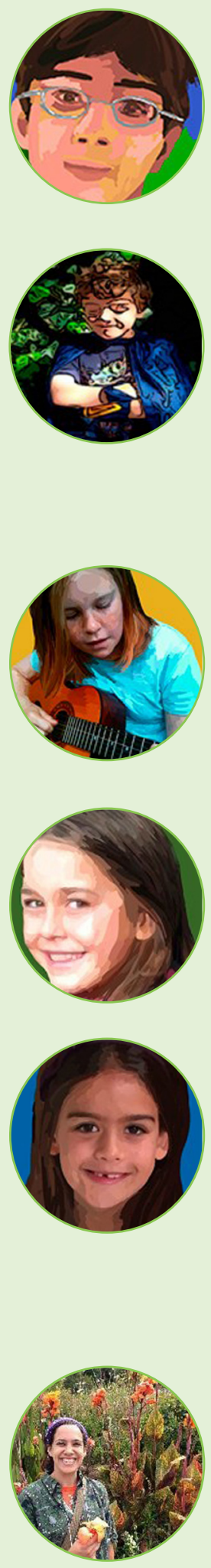

\section{DARIUS, 13 YEARS OLD}

I am 13 years old and in the eighth grade. In my free time I enjoy reading, backpacking, and playing the trumpet and piano. I am passionate about the environment and community service. I am very interested in public speaking and am in my school's debate team. I enjoy learning about science, particularly neuroscience, chemistry, biology, and physics.

\section{WYATT, 10 YEARS OLD}

I am a fourth grader in Piedmont, CA, USA. I like to read, play with Legos, play Minecraft, and eat and sleep! I also love scootering, biking, hiking, and building stuff. My favorite food is Ethiopian - I love the whole fried fish and the doro tibs. My favorite subjects in school right now are computer lab, P.E., library, and science. I am looking forward to taking chemistry when I get to middle school! After college, I want to be a mechanical engineer and robotics programmer.

\section{SCHUYLER, $\|$ YEARS OLD}

I am Schuyler. I live in Berkeley, CA, USA. I am 11 years old and in the seventh grade. My favorite subjects in school are writing and science. I like to write fictional pieces, and I also like to sing, act, and cook. Someone who I look up to and who inspires me is my mom. I also play soccer and basketball.

\section{SYBILLE, 8 YEARS OLD}

I am Sybille. I am 8 years old and in fourth grade at Malcolm X. I live in Berkeley, CA, USA and I play soccer. I like doing silly science experiments and cooking, and I am really good at math.

\section{PACEYN, 7 YEARS OLD}

I am Paceyn. I am 7 years old and I am in second grade at LeConte Elementary in the TWI Spanish program. My favorite subjects in school are Reading, Writing, and Math. I like doing science experiments, making art, and writing stories, especially poems and songs. I collect rocks and stuffed animals, and I like skiing and cold weather. I enjoy doing gymnastics, dance, and cheersport, and I have a pet guinea pig named Luna.

\section{AUTHORS}

\section{RIVA ANNE BRUENN}

Riva Bruenn is a Ph.D. candidate in the Plant and Microbial Biology Department at the University of California, Berkeley. Riva studies floral symmetry in the tropical ginger order Zingiberales. Riva has served as a graduate student instructor for Plant Morphology and the introductory plant biology course The Secret Life of Plants. She has been active in several science outreach organizations including Expanding Your Horizons, Be a Scientist, Bay Area Scientists in Schools, and Planting Science. She is currently collaborating with educators involved in ARBOR to create content useful to high school and community college students learning about evolution. She is passionate about Science education and outreach, and about the accessibility of Science to nonresearchers. *rbruenn@berkeley.edu 


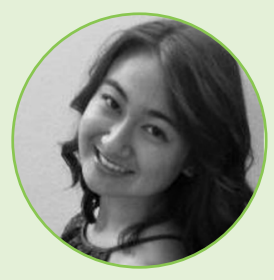

\section{VALERIE LAVENBURG}

Valerie Lavenburg is working toward earning her Bachelor's degree in Integrative Biology at the University of California, Berkeley. Currently, she is a research intern at the Wu Lab, which is part of the Produce Safety and Microbiology Unit at the USDA. Previously, she was a member of the Specht Lab at UC Berkeley, which focuses on plant evolution. Lavenburg's project was to build fossil-calibrated phylogenies for Zingiberales and African Costus. She also worked in the Somerville Lab at the Energy Biosciences Institute (UC Berkeley), where her project involved characterizing mutants involved in cell wall biosynthesis. Lavenburg is interested in studying plant biology to improve technologies related to sustainable energy and food.

\section{SHAYLA SALZMAN}

I am interested in the evolution and molecular mechanisms that underlie plant-insect interactions. Specifically, I hope to ask what is the molecular basis of cross-species interactions and how has the evolution of these interactions shaped the diversity that we see today. I am currently studying Zamia cycads and their weevil pollinators and lepidopteran herbivores with Naomi Pierce and Robin Hopkins at Harvard University. This system is particularly interesting in their apparent species-specific pollinator interactions, highly toxic plant tissue, and threatened conservation statuses. 